\title{
Applications of Finite Element Simulation in the Development of Advanced Sheet Metal Forming Processes
}

\author{
Sandip Jadhav, Martin Schoiswohl, and Bruno Buchmayr \\ Lehrstuhl für Umformtechnik, Montanuniversität Leoben, Loeben, Austria \\ Received December 15, 2017; accepted January 21, 2018; published online February 5, 2018
}

\begin{abstract}
Sheet metal forming is widely used in automotive, aviation, packaging, and household goods. It is most popular for the manifold technical feasibilities in manufacturing, high precision, mass production, and short processing time. Modern automotive concepts demand a weight reduction by using high strength materials and excellent crash performance, which requires innovative simulation techniques in the design and development phase as well as suitable processing chains. The conventional manufacturing planning method takes a lot of time, hence the Finite Element method (FEM) is applied to reduce the lead time. The FEM prediction accuracy depends on the proper selection of a material model, quality of input parameters, actual operating conditions, and many other factors. This study involves new developments in the sheet metal forming technology, the most influencing factors of the forming process and case studies to justify it. The first case study explains the springback analysis and springback compensation of AIMgSi (6xxx series)-panels. The second case study describes the thickness analysis and deformation behaviour of patchwork blanks for hot stamping processes.
\end{abstract}

Keywords: Sheet metal forming, Material model, Forming simulation, Springback, Forming limit diagram, Hot stamping

\section{Anwendungen der Finite-Elemente-Simulation für die Entwicklung hochwertiger Blechumformprozesse}

Zusammenfassung: Blechumformung findet ihre Anwendung sehr häufig in den Bereichen Automobilbau, Luftfahrt, Gehäusebau und Haushaltswaren. Die Bedeutung beruht auf den vielfältigen technischen Fertigungsmöglichkeiten, der hohen Präzision, der Tauglichkeit zur Serienfertigung und den kurzen Taktzeiten. Moderne Konzepte des Automobilbaus verlangen nach Gewichtseinsparungen durch

S. Jadhav $(\bowtie)$

Lehrstuhl für Umformtechnik,

Montanuniversität Leoben,

Loeben, Austria

sandip.jadhav@unileoben.ac.at
Verwendung von hochfesten Materialien und exzellentem Crash-Verhalten, was innovative Simulationstechniken im Stadium des Designs und der Prozessentwicklung sowie passende Fertigungsketten erfordert. Konventionelle Methoden der Fertigungsplanung sind zeitaufwändig, weshalb Finite Elemente Methoden (FEM) zur Senkung der Bearbeitungszeiten angewandt werden. Die Vorhersagegenauigkeit der FEM-Rechnung hängt dabei von der Wahl eines geeigneten Materialmodells, von der Qualität der Eingabeparameter, den tatsächlichen Prozessbedingungen und einigen anderen Faktoren ab. In dieser Arbeit werden neuere Entwicklungen der Blechumformtechnologien und die wichtigsten Einflussfaktoren dargestellt sowie mit Fallstudien belegt. Die erste Fallstudie erklärt eine Rückfederungsanalyse inklusive deren Kompensation an einem AIMgSi (6xxx)-Blechteil. Die zweite Studie beschreibt eine Wandstärkenanalyse und das Verformungsverhalten eines sog. Patchwork-Teils für das „hot stamping”.

Schlüsselwörter: Blechumformung, Werkstoffmodel, Umformsimulation, Rückfederung,

Grenzformänderungsschaubild, Warmtiefziehen

\section{Introduction}

The body-in-white and most of the structural components of vehicles are manufactured by sheet metal forming. It offers a high strength to weight ratio compared to bulk metal forming. The automotive industry is also confronted with fulfilling the crash requirements for front crash, roof crash, or side impact. To achieve a high level of safety, some key parts like B-pillar, front side member, and cross members demand a high ratio of strength to weight. These requirements could be met with high strength aluminium alloy; due to lower formability behaviour, however, these alloys are still in the developmental stage $[1,2]$. To solve fabrication problems, thermomechanical treatments could be used, and these could be analyzed using finite element techniques [3]. 
The initial study focuses on the mechanical testing and material modeling. The significance of the input parameters for sheet metal simulations are discussed in detail. In the last section, two case studies are presented showing the challenges in springback compensation and hot stamping of patchwork blanks.

\section{Material Properties and Material Modelling}

Nowadays, ultra-high strength steel grades (UHSS) and high strength aluminium alloys are used to manufacture BIW parts. Forming (deep drawing) of these materials at room temperature is a challenging task. To get accurate results of the FEM analysis, a proper material model is essential. This section focuses on the material properties and material models for a sheet metal forming simulation. The most important criteria for adequate material modelling are hardening coefficient, yield strength, and material failure.

In the sheet metal simulation, two aspects of modelling are of interest. The first characterises the flow behaviour of the sheet and the second predicts the forming limit under defined conditions [4]. The yield locus is used to describe the plastic behaviour of the sheet metals with a normal plastic anisotropy. Liao [5] explains the influences of the yield surface shape and plastic anisotropic parameter on the, punch force, strain distribution, and localisation for punch stretching operations.

The second model defines the upper limit of forming (local necking or cracking) in the deformed sheet. The Forming Limit Diagram (FLD) is a curve representing the upper limit of the safe zone, which is obtained by deforming sheets up to local necking in different strain conditions, like uniaxial compression, pure shear, uniaxial tension, plane strain, and equi-biaxial tension.

\subsection{Flow Behaviour of Metal}

To avoid time-consuming trial and error processes, the formability of materials is analysed by FE techniques. The material is forced to an elastic and a plastic deformation, which is usually determined by an uniaxial tensile test. Accurate data are required to predict the formability limit and the springback.

\subsection{Elastic Stress States-Young's Modulus}

The springback behaviour is primarily dependent on the elastic properties. For most of the steel sheets, a Young's Modulus of $210 \mathrm{GPa}$ is used.

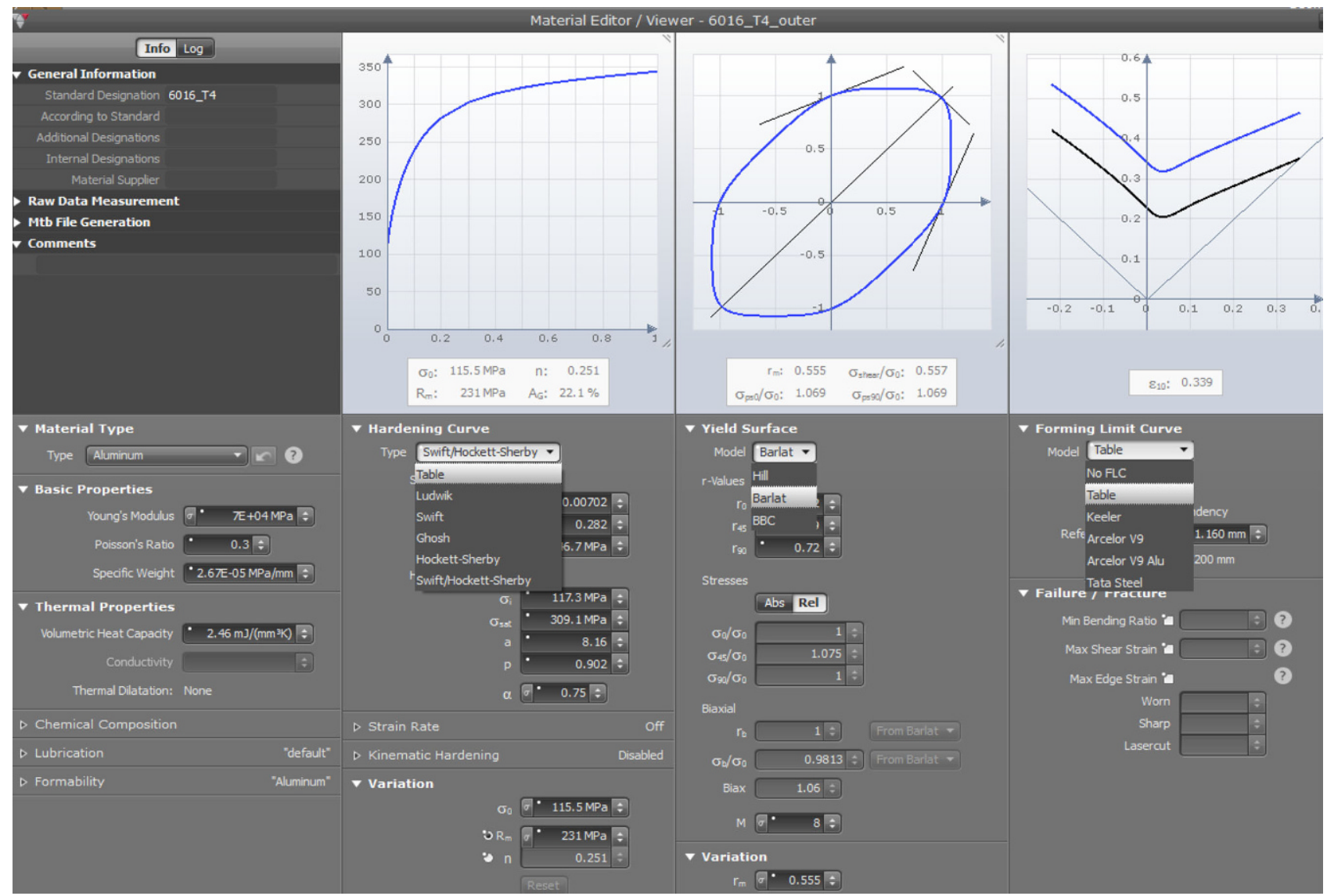

Fig. 1: Material modelling in AutoForm [6] 


\begin{tabular}{|llllllll}
\hline \\
TABLE 1 \\
Chemical composition of alloy & AA6451 in weight percent & & & & & \\
\hline $\mathrm{Al}$ & $\mathrm{Mg}$ & $\mathrm{Si}$ & $\mathrm{Mn}$ & $\mathrm{Cr}$ & $\mathrm{Cu}$ & $\mathrm{Zn}$ & $\mathrm{Fe}$ \\
\hline $96.5-98.95$ & $0.40-0.80$ & $0.60-1.00$ & $0.05-0.40$ & $\leq 0.10$ & $\leq 0.40$ & $\leq 0.15$ & $\leq 0.40$ \\
\hline
\end{tabular}

\begin{tabular}{|c|c|c|c|c|c|c|c|c|}
\hline \multirow{2}{*}{$\begin{array}{l}\text { Density } \rho \\
{\left[\mathrm{g} \cdot \mathrm{cm}^{-3}\right]}\end{array}$} & \multirow{2}{*}{$\begin{array}{l}\text { Young's modulus, E } \\
\text { [GPa] }\end{array}$} & \multirow[t]{2}{*}{ Poisson's ratio, $v$} & \multicolumn{3}{|c|}{ Yield strength $\sigma_{y l d}[\mathrm{MPa}]$} & \multicolumn{3}{|c|}{ r-value } \\
\hline & & & $0^{\circ}$ & $45^{\circ}$ & $90^{\circ}$ & $0^{\circ}$ & $45^{\circ}$ & $90^{\circ}$ \\
\hline 2.7 & 70 & 0.30 & 151.3 & 171.2 & 163.6 & 0.62 & 0.33 & 0.80 \\
\hline
\end{tabular}

\subsection{Flow Curve and Strain Hardening}

The initial flow stress and the strain hardening are critical for the ductility and strength behaviour. The strain hardening exponent $n$ in Ludwik's law describes the ability to involve the surrounding material in the deformation process and to avoid local deformation. A higher $n$-value induces an improved ductility and a better stretchability of a sheet metal. Soft materials usually show a high $n$-value, where high strength materials have a low one. For the FEM-approach, S. Bruschi [4] divides strain hardening into four different types: (a) isotropic strain hardening, (b) kinematic hardening, (c) rotational hardening, and (d) distortional hardening.

Fig. 1 shows the input required to build up a new material. The flow curve is described by a hardening function as defined by Ludwik, Swift, Ghosh, Hockett-Sherby, Swift/ Hockett-Sherby and an approximation of tensile test data.

\subsection{Anisotropy}

Anisotropy ( $r$-value or Lankford value) is an important property for deep drawing and plays a key role in the formability of sheets. The anisotropy is the variation in material properties with respect to the direction due to the variation of the microstructure. In the rolling process, grains are elongated in the direction of rolling, so microstructural variation happens. r-values are calculated from the uniaxial tensile test by measuring strain in length and cross direction

$$
r \text { (Normal Anisotropy })=\frac{\ln \frac{w_{f}}{w_{i}}}{\ln \frac{t_{f}}{t_{i}}}=\frac{\text { True width strain }}{\text { true thickness strain }}
$$

w width of the sheet [mm]

$\mathrm{t} \quad$ thickness of the sheet [mm]

$r=1$ means that both strains are equal, which is called isotropic hardening. Generally, for aluminium alloys, $r$-values are less than unity, whereas r-values for steel sheets greater than 2 are not uncommon. Hypothetically, when $R=\infty$, then the thickness strain is zero, which means that there will be no thinning during the tensile deformation, which is why high r-values are preferred in sheet metal forming.
In biaxial forming operations, like deep drawing of a cup, a non-uniform anisotropy may result in the earing phenomena. The top edge is reflected in an undulated manner. The anisotropy is also strongly influencing the forming limit. The residual stresses after forming and springback are intensely dependent on the anisotropy of the material, e.g. the plastic strain is microscopically distributed in the neighbouring grains in a non-uniform manner [7].

\subsection{Yield Surface}

The yield surface defines the multi-axial stress condition in which the material starts to yield. There are different models to define the yield surface. Models by Tresca, von Mises, Hill, Barlat, and Banabic are widely used to define the yield surface [8]. Von Mises and Tresca assume that the material is homogenous, i.e. it is 'isotropic'. In reality, the microstructure of the sheet metal depends on the rolling operation, which results in the directional dependency in the plastic properties ( $r$-value). Fig. 1 shows the Hill, Barlat, and Banabic yield criterion to define the anisotropic yield surface correctly. In an anisotropic yield function, sheet metals are considered to be orthotropic.

\subsection{Forming Limit Diagram}

The forming limit diagram (FLD) is extensively used in sheet metal applications for a failure prediction. The curve represents the maximum values of principle strains $\varepsilon_{1}$ and $\varepsilon_{2}$ determined by measuring the strains at material failure. The different methods for determining the forming limit curve have been proposed by the Nakazima test, hydraulic bulge test, Marciniak test, and others [9]. At LUT, a Zwick BUP 200 system is taken to measure FLDs in combination with an optical device, a GOM Aramis system, to measure the strain field on the test sample and to determine the major strains at the begin of necking.

Fig. 1 shows the five different options available to generate FLC in AutoForm. The Keeler model is used for low carbon steels. The Arcelor V9 FLC model is used for steels having a tensile strength ranging from 260 to $1500 \mathrm{MPa}$ and sheet thicknesses ranging from 0.5 to $3.5 \mathrm{~mm}$. For the Keeler model, the input has to be defined from the tensile data in the $90^{\circ}$ direction. The Arcelor V9 Alu model used for aluminium with a sheet thickness ranging from 
Fig. 2: Formability analysis of an Aluminium panel. a Shape of Al-panel, $\mathbf{b}$ results of formability calculation
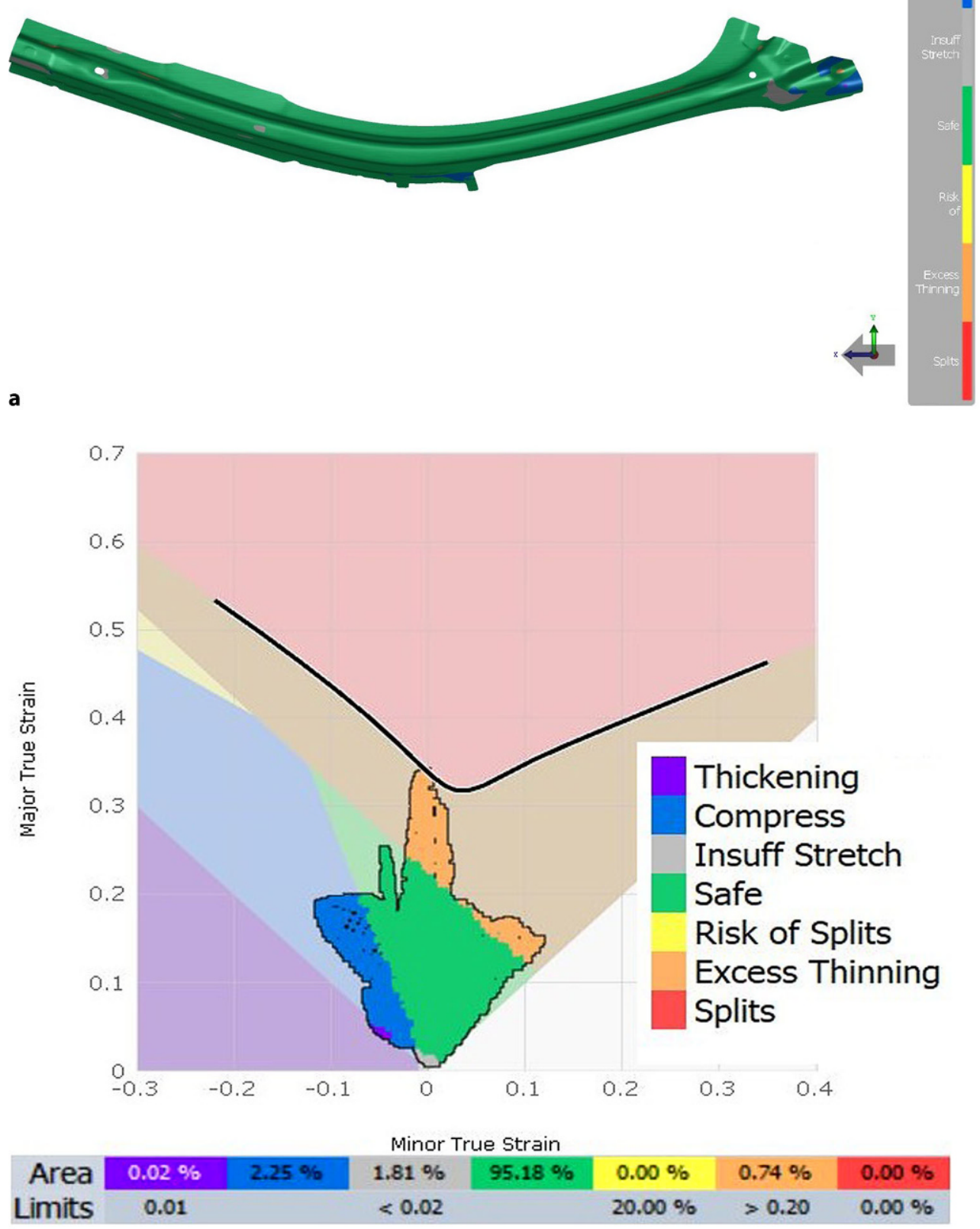

b

0.5 to $3.5 \mathrm{~mm}$. The Tata steel FLC model is applicable for steels having tensile strengths between 260 to $1500 \mathrm{MPa}$ and sheet thicknesses ranging from 0.2 to $3.0 \mathrm{~mm}$. In the table option, experimental FLC data can be imported out of a file with two columns representing the minor strain and the major strain.

\subsection{Friction Conditions}

Tribology also plays a key role in the sheet metal forming process. The surface roughness, quantity of lubrication, forming speed, blank-holder-force, and other factors involved during the forming process are combined in the tribological behaviour of sheet metal forming. The friction condition has an effect on the surface quality of the prod- 
Fig. 3: Springback distribution after trimming operation
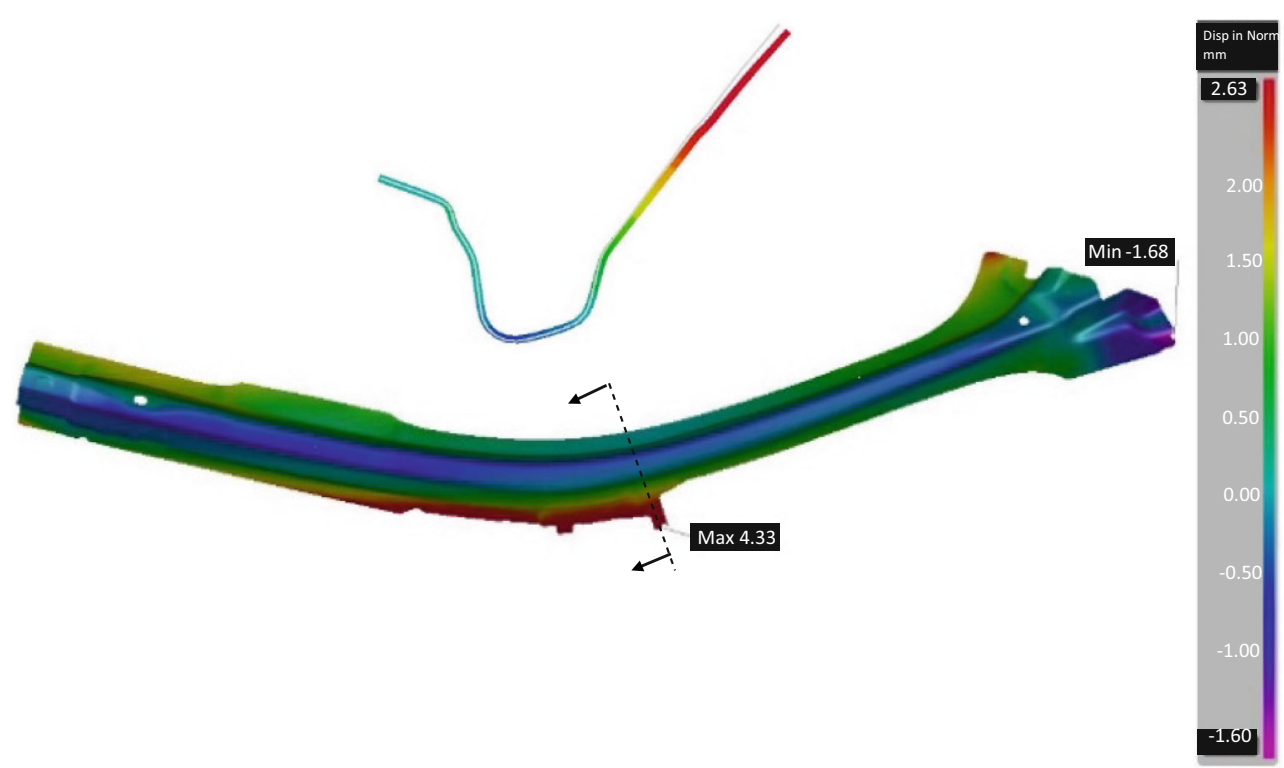

Fig. 4: Influence of the coefficient of friction on springback

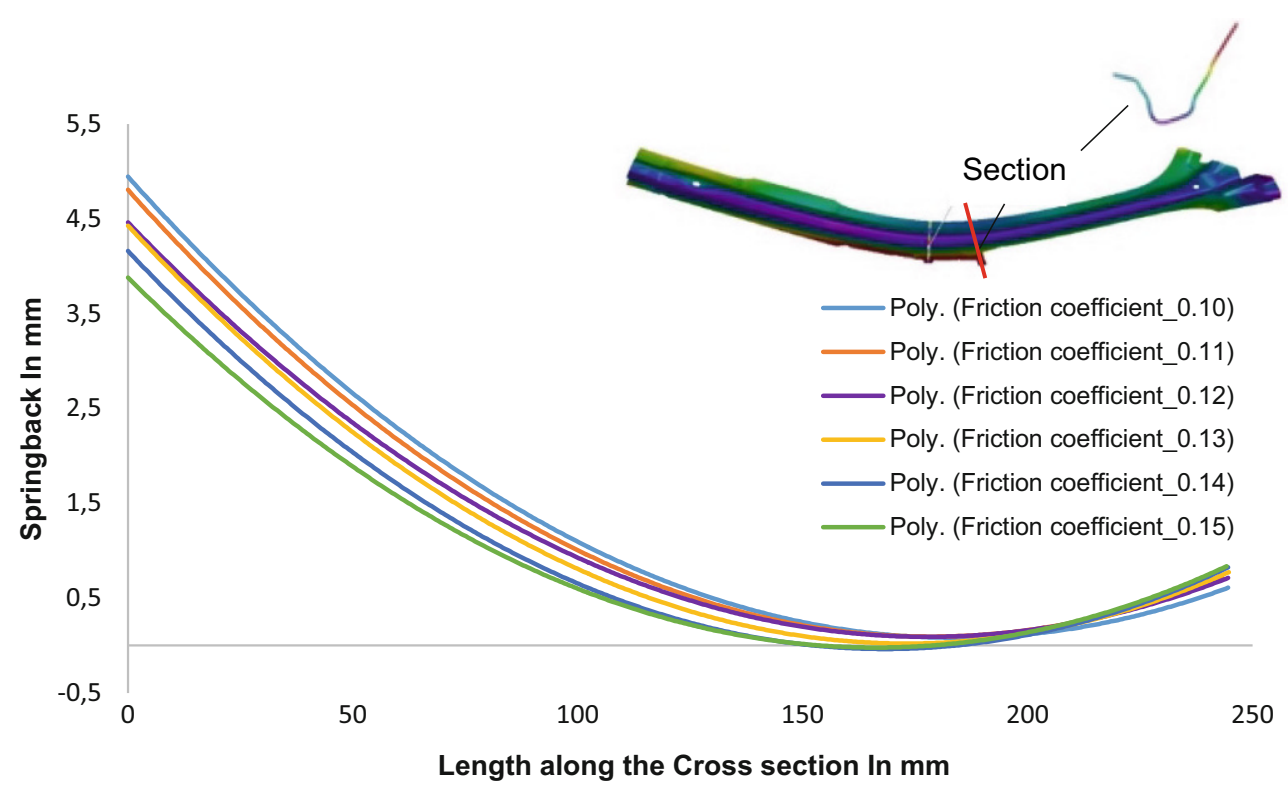

uct, tooling life, efficiency, and stability of processes. Draw bead testing, as applied at our lab, helps to characterise different tribological conditions and to obtain accurate input data.

\section{Springback Analysis and Compensation}

\subsection{Case Description and Input Parameters Used for an Aluminium Panel}

When the part is released from the forces of the deep drawing tool, Springback occurs and leads to some geometric difficulties during the joining or assembling of parts. The most important parameters for springback are the Young's Modulus, material strength, tool radius, and blank holder force. For aluminium, springback behaviour

is more complex because of its strong plastic anisotropy and low Young's modulus $[10,11]$.

The objective of this case study is to predict the springback in the body panel manufactured from AluminiumMagnesium-Silicon alloy (6xxx). Aluminium alloys of type $6 x x x$ are used for automotive applications because of their favoured properties, like cold formability, precipitation hardenability, weldability, and corrosion resistance. The chemical composition and material properties of the selected AA6451 aluminium alloy are given in Table 1 and 2, respectively.

The AutoForm R-7, FE package is used to analyse the springback and formability of an aluminium panel. First of all, CAD geometries of deep drawing tools and blank are imported. The material model for AA6451 is developed by given material properties. In the production plan, deep drawing, trimming and spring back measurement operation 
Fig. 5: Influence of clearance on springback
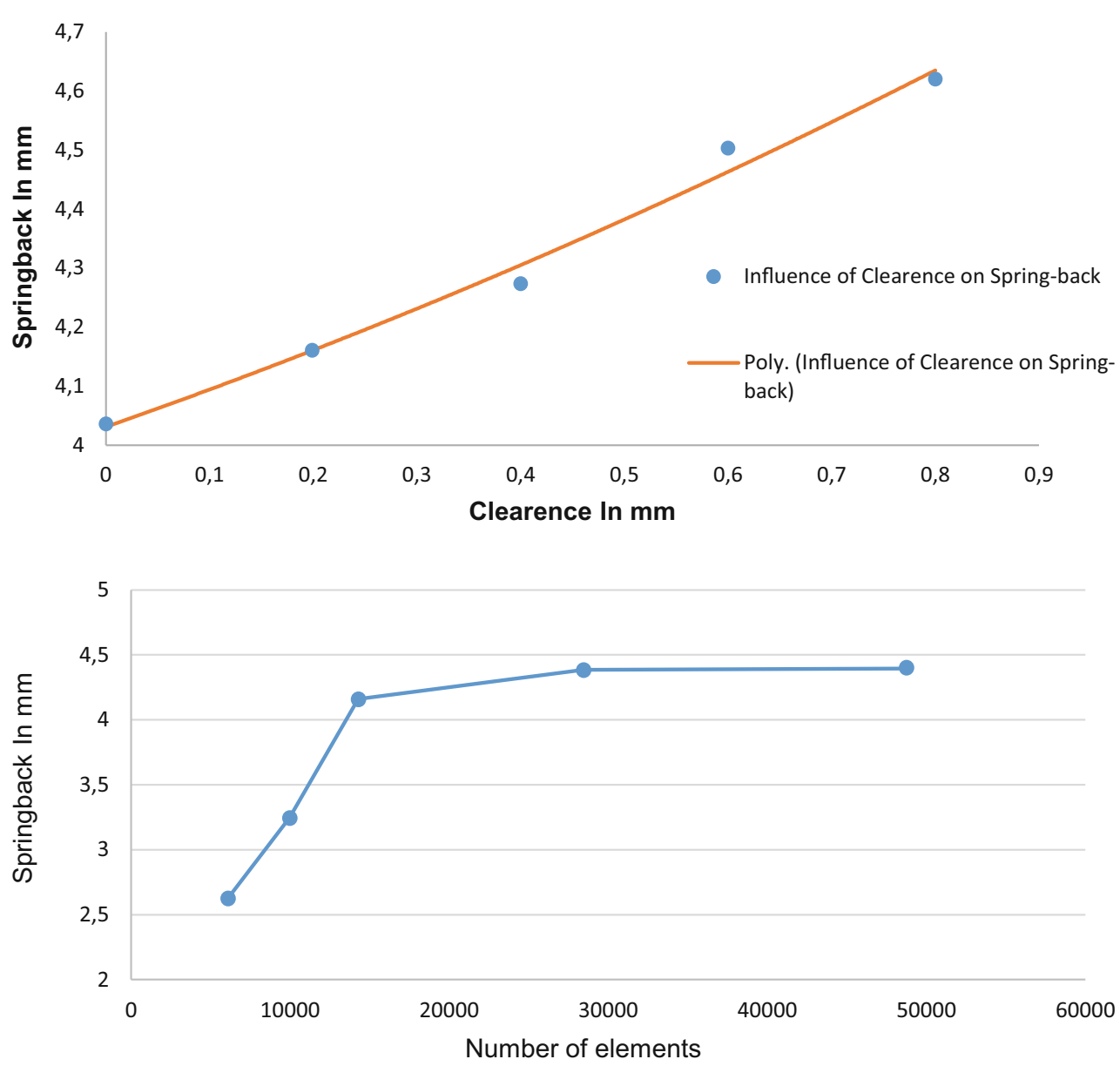

Fig. 6: Influence of the number of elements on the springback result

TABLE 3

Chemical composition of press hardened steel 22MnB5 in weight percent

\begin{tabular}{llllllll}
\hline C & Si & Mn & P & S & Al & Nb & \\
\hline 0.21 & 0.28 & 1.18 & 0.015 & 0.001 & 0.03 & 0.0032 & 0.18 \\
\hline
\end{tabular}

\begin{tabular}{|c|c|c|c|c|c|c|c|c|c|}
\hline \multirow[t]{2}{*}{$\begin{array}{l}\text { Density } \rho \\
{\left[\mathrm{g} \cdot \mathrm{cm}^{-3}\right]}\end{array}$} & \multirow[t]{2}{*}{$\begin{array}{l}\text { Young's modulus } \mathrm{E}, \\
20^{\circ} \mathrm{C}[\mathrm{GPa}]\end{array}$} & \multirow[t]{2}{*}{$\begin{array}{l}\text { Young's modulus, E at } \\
950^{\circ} \mathrm{C}[\mathrm{GPa}]\end{array}$} & \multirow[t]{2}{*}{$\begin{array}{l}\text { Poisson's } \\
\text { ratio, } v\end{array}$} & \multicolumn{3}{|c|}{$\begin{array}{l}\text { Yield strength } \sigma_{y l d} \\
{[\mathrm{MPa}]}\end{array}$} & \multicolumn{3}{|c|}{ r-value } \\
\hline & & & & $0^{\circ}$ & $45^{\circ}$ & $90^{\circ}$ & $0^{\circ}$ & $45^{\circ}$ & $90^{\circ}$ \\
\hline 7.8 & 210 & 45 & 0.3 & 81.3 & 79.4 & 84.5 & 0.7 & 0.9 & 0.8 \\
\hline
\end{tabular}

are built in sequence. Input parameters, like lubrication condition, friction coefficient, ram velocity, blank holding force, and stroke, are defined in the process stage. In the control stage, different preferences are available and these directly affect the simulation accuracy. These preferences include selection of engineering phase, element size, element type, element refinement level, time step control, and more.

In this example, the aluminium panel is manufactured by two operations: deep drawing and trimming. The sigma optimisation simulations are run to check the crack formation, wrinkles, thinning, and springback. The AutoForm sigma optimisation deals with the robustness analysis of the forming process. In the process development stage, input design parameters are provided in terms of part radii, binder surface geometry, addendum geometry, draw beads, blank holding force, lubrication, and more. The AutoForm sigma optimisation runs multiple stamping simulations. During these simulations, design parameters are automatically varied with a focus on quality requirement (like no cracks, no wrinkles, sufficient starching). So it is beneficial to quickly determine the influence and sensitivity of design parameters and process optimisation. Once a sigma optimisation concept is ready and the part is principally feasible for fabrication, the die design has to be changed to compensate the springback. The com- 


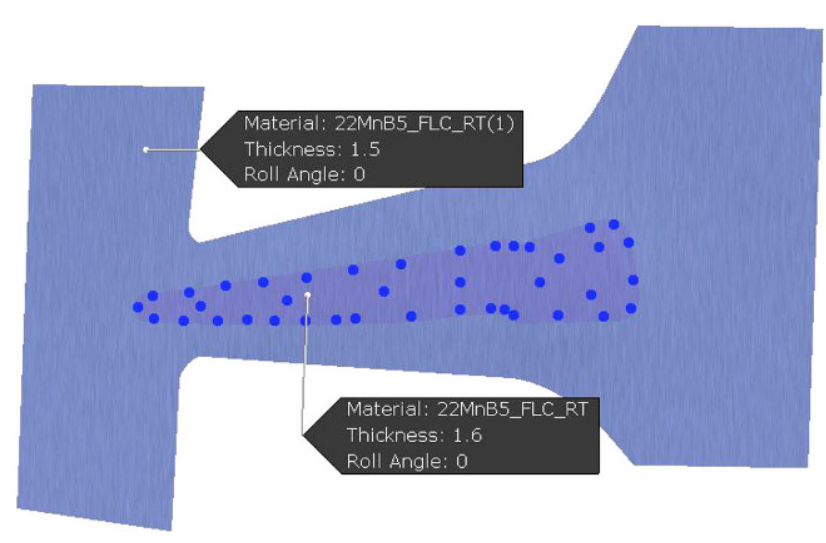

Fig. 7: Patchwork blank showing Initial positions of weld-spots

pensated area is divided into three different zones: first, compensated directly, second, the binder area marked as fixed and it remains unchanged, and third, a transient area (addendum). The actual compensation is calculated for each node of the element by an efficient algorithm, which is implemented in Autoform. The compensation geometry of the die face is provided with the same value in the opposite direction of the springback. Then the compensated tool geometry is used as an input for the next simulation.

\subsection{Results and Discussion}

The formability analysis is performed by multiple iterations using sigma optimisation simulations. Fig. 2 shows the different zone of the FLD and corresponding areas. $95.18 \%$ of the elements are under the safe zone, $2.25 \%$ of elements are under the compression, $1.81 \%$ of elements are under the insufficient stretch, and $0.74 \%$ of elements are under excess thinning zone in the FLD. These results show that the deep drawing process designed above is feasible. At the end of the manufacturing process (after the trimming operation), the final springback distribution is calculated. The springback distribution is shown in Fig. 3. The maximum value of the springback is $4.33 \mathrm{~mm}$, and a label is used to address it. The sheet position before and after the springback is compared at the cross section. Using the springback compensation module of AutoForm, it is possible to reduce the final springback to $2.66 \mathrm{~mm}$ after three iterations.

As mentioned before, there are many factors which influence the springback behaviour. Therefore, a parametric study of the friction coefficient clearance between die and punch is performed in this case. In this study the friction coefficient is varied at equal intervals of 0.01 in between 0.10 and 0.15 . Fig. 4 shows that a higher coefficient of friction results in a lower springback in the aluminium panel. This is due to the fact that the existence of friction is beneficial to reduce the rebound.

In a second case, the gap between the forming tools are varied from 3.2 to $4.0 \mathrm{~mm}$, which gives a clearance varying from 0 to $0.8 \mathrm{~mm}$. Fig. 5 shows that the springback increases approximately linearly with the increase in the clearance for all cases. The maximum springback is found with a higher value of clearance.

A mesh sensitivity analysis is also carried out by increasing the number of the elements of the blank. In this study, the element size varies between $10 \mathrm{~mm}$ and $50 \mathrm{~mm}$, the corresponding number of elements is noted and the springback value is calculated at the end of the trimming operation. In Fig. 6, the springback value is plotted against the

Fig. 8: Formability analysis of a B-pillar
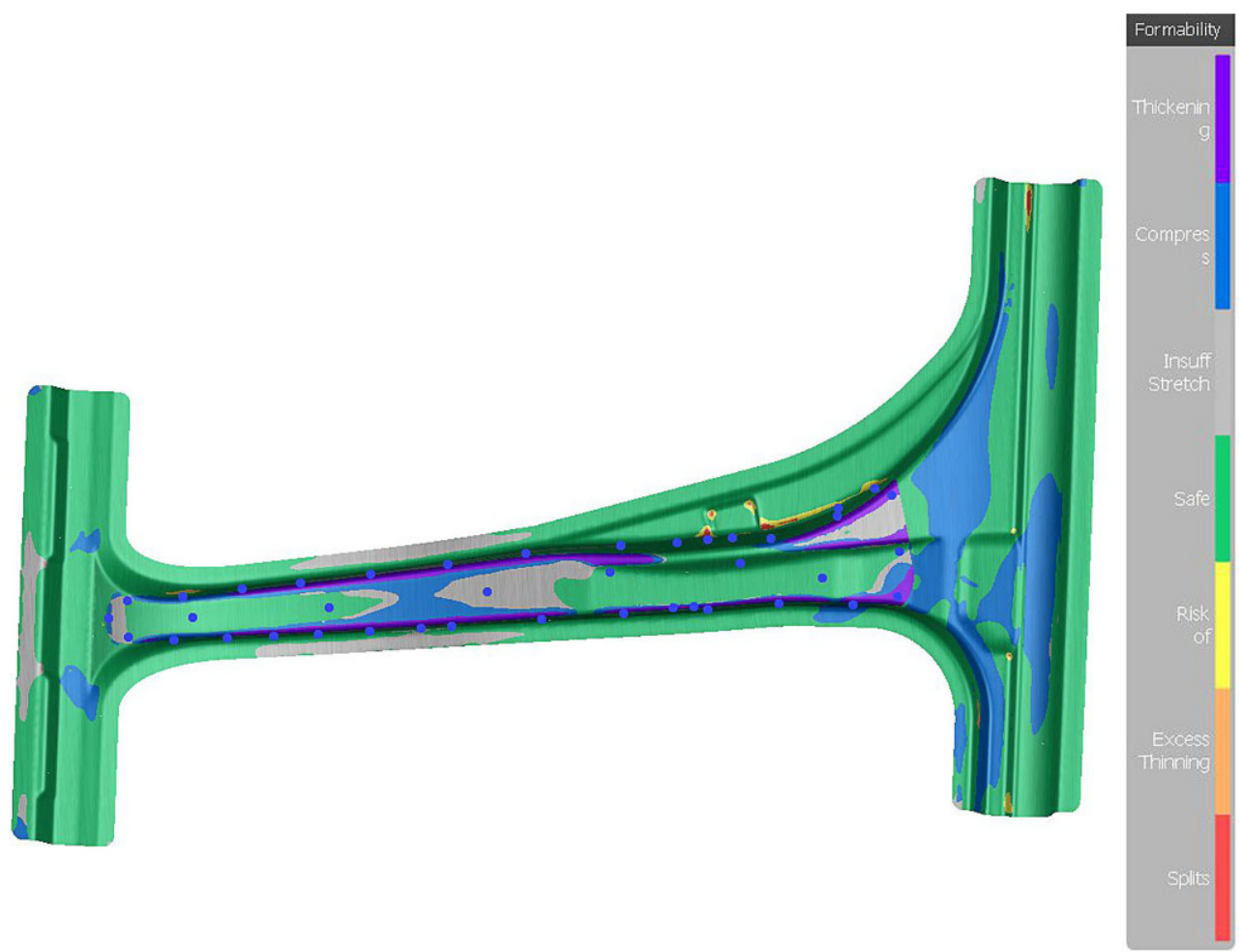

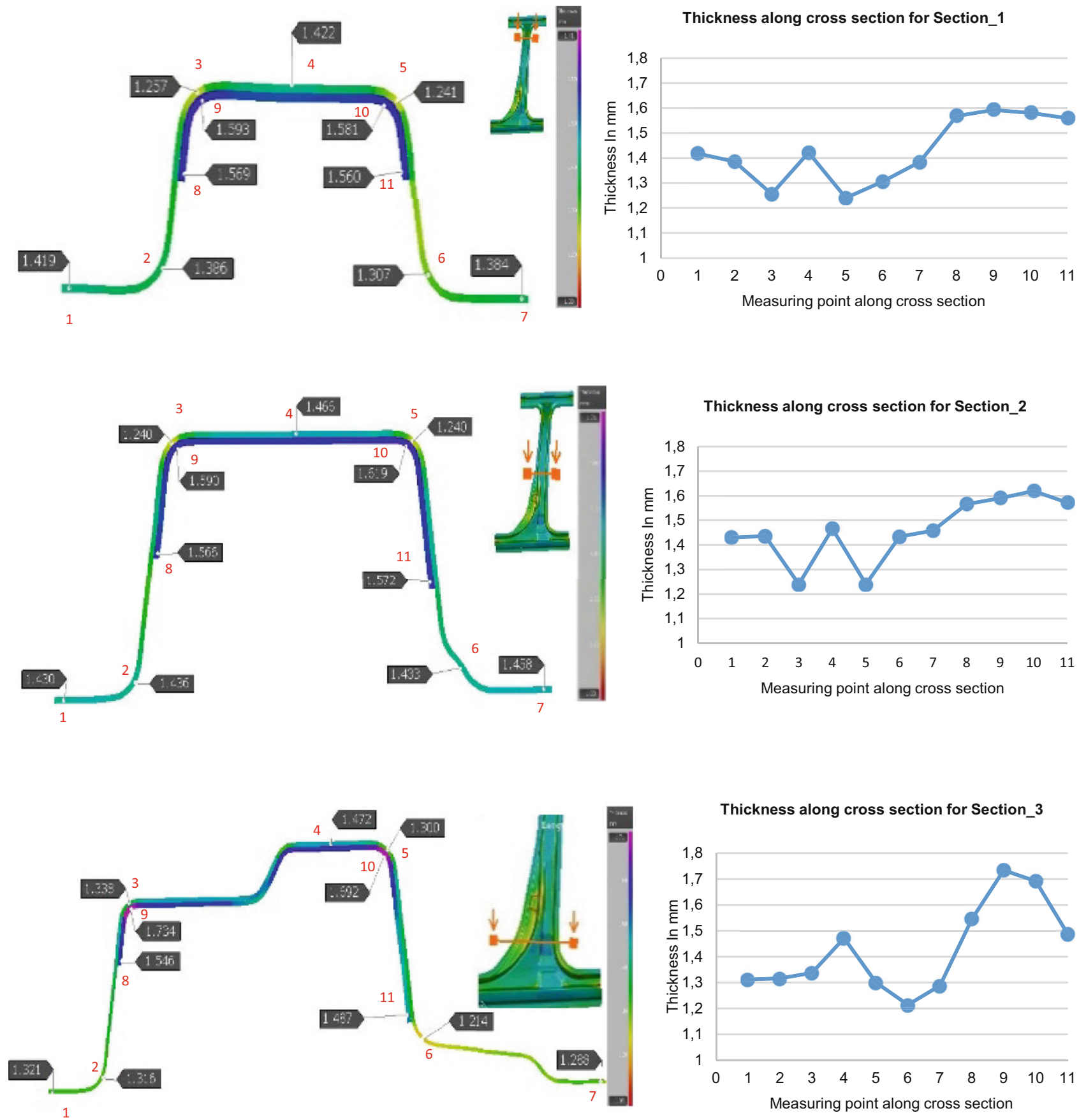

Thickness along cross section for Section_3

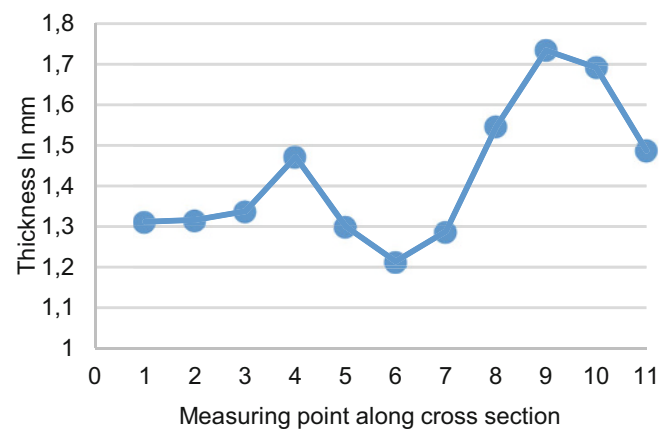

Fig. 9: Thickness at cross section 1,2 and 3

number of elements. The plot shows that nearly 30,000 elements (element size of $20 \mathrm{~mm}$ ) are required for the converged springback results.

\section{FE Analysis of Patchwork Blank Hot Stamping Process}

The requirements for ultra-high strength steel parts are being increased to meet emission standards and crash performance. Tailor-welded blanks from a combination of heat- treatable and non-heat-treatable steel are used to generate specific characteristic parts like B-pillar, body side outer, cross-members, A-pillar and side members, and more [12]. Tailored blanks are divided into tailor-welded blanks, tailor-rolled banks, tailored tempering blanks, and patchwork blanks. Of these tailored blanks, the patchwork blanks are more flexible to get the required mechanical properties of components. In patchwork blanks, the main blank and patched blank are joined by spot welding prior to the hot stamping process. Patched blanks are generally smaller than the main blank, and in some cases more than one 

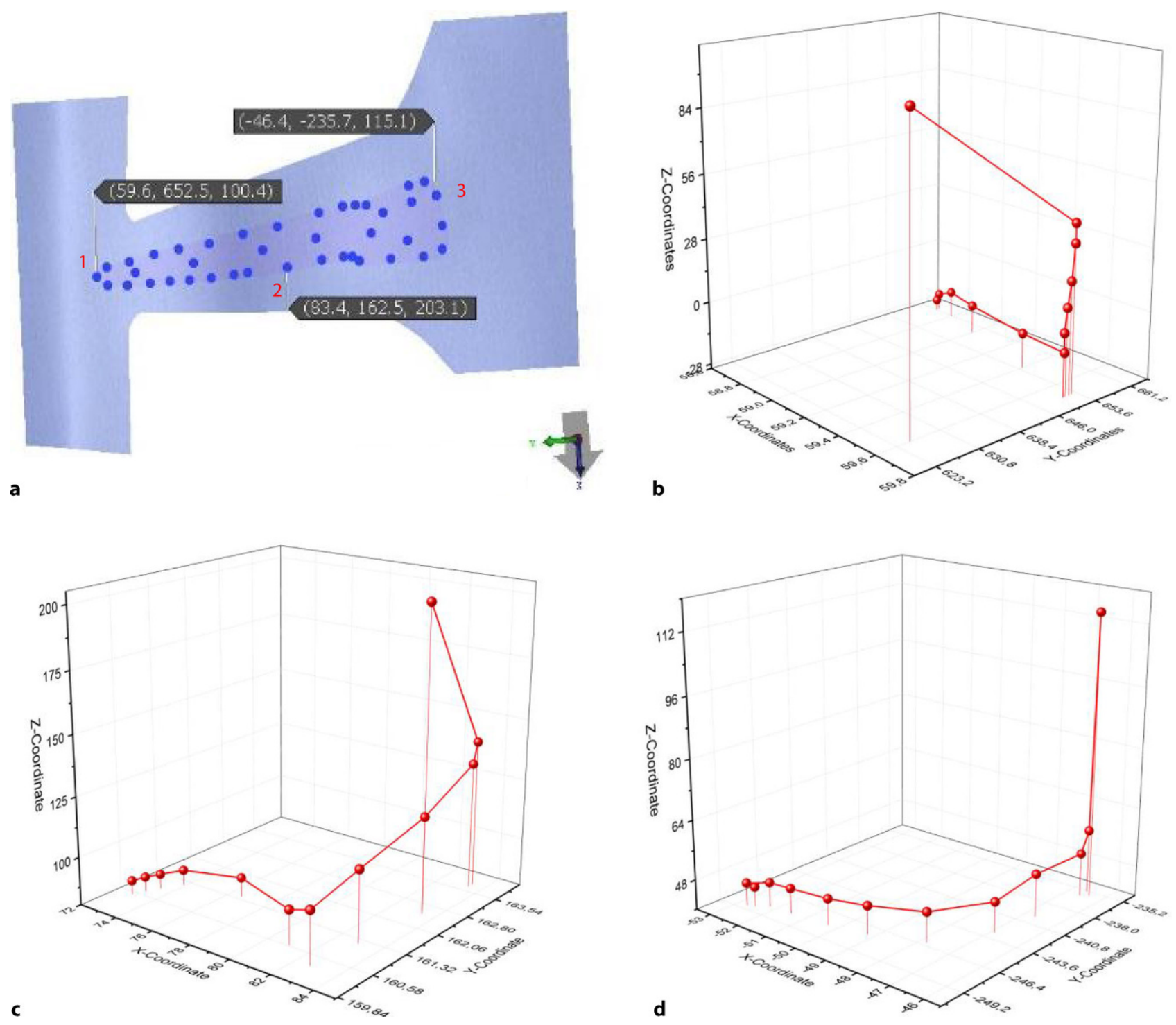

Fig. 10: Draw-In analysis of patchwork blank. a Weld-spot location on the blank; b Position of Weld-spot 1; c Position of Weld-spot 2; d Position of Weld-spot 3 in deep drawing processes

piece of patched blanks are used. The specific location and numbers of spot-welds are essential to avoid the manufacturing defects [13]. Ahmad and Zakaria [14] studied an optimisation of spot-welds on patchwork blanks for the hot stamping process. This case has been used for further numerical investigations.

\subsection{Case Description and Input Parameters Used}

In this case study, thermo-mechanical coupled FE simulations are performed to predict the thickness distribution, wrinkles, and flow behaviour of weld spots in patchwork blanks. Two different blanks of $22 \mathrm{MnB} 5$ with 1.5 and $1.6 \mathrm{~mm}$ thickness are used for manufacturing a B-pillar. The chemical composition and material properties of $22 \mathrm{MnB} 5$ are shown in Tables 3 and 4 . In the hot stamping process, a blank is initially heated up to $950^{\circ} \mathrm{C}$ to its austenitic tem- perature. Then it is placed in room temperature forming die and followed by simultaneous forming and quenching.

In the FE simulation, the main blank and patched blank are built separately. The connection between the main blank and patched blank are modelled with the welding points. The layout of welding spot should be designed according to the geometric shape and blank thickness to prevent the wrinkles. The size of the patchwork blank is defined according to the requirement of the strength and deformation behaviour of the component. The sketch of the main blank, patched blank, and location of spot weld is shown in Fig. 7.

\subsection{Results and Discussion}

Wrinkles and cracks are the major defects in the deep drawing of the patchwork blank. Fig. 8 shows a formability anal- 
ysis of a hot stamped B-pillar manufactured from a patchwork blank. Wrinkling usually occurs in the middle region. This is because of the material flow as well as the deformation behaviour of the patchwork blank. The material flow and deformation behaviour is strongly dependent on the design of weld-spot and part geometry. Three cross-sections are selected on the formed part to analyse the thickness distribution Fig. 9a-c. shows the selected measuring point along the three cross-sections and the corresponding thickness value. Points 9 and 10 are on the patch (inner side of punch corner), and the highest thickness in each crosssection is shown. Points 9 and 10 are under the thickening and compression zone in the forming limit diagram. Points 3,5 , and 6 are on the outer corner of the punch, and the thinning at each cross-section is shown. Points 3-9 and 5-10 prove the theory of simple bending. Fig. 10 shows the strip draw-in of the patchwork blank, which is useful for understanding the flow behaviour and final position of the weld-spot in the deformed component. Three weld-spots are selected for the draw-in analysis, two are in the end position of the blank and one in the central position. The plot shows the three dimensional position of the weld-spot in the whole deep drawn process. The Z-coordinate represents the deep drawing direction, the $X$-coordinate represents the rolling direction of the sheet. Plot 10-b shows the flow behaviour of sheet at Weld-spot 1. After a punch stroke of $125 \mathrm{~mm}$, the sheet (weld-spot) moves $1 \mathrm{~mm}$ in the rolling direction and $35 \mathrm{~mm}$ in the Y-direction. In Plot 10c, Weld-spot 2 sheet moves $10.5 \mathrm{~mm}$ in the rolling direction and $2 \mathrm{~mm}$ in the Y-direction. In Plot 10-d the Weld-spot 3 sheet moves $6 \mathrm{~mm}$ in the rolling direction and $13 \mathrm{~mm}$ in the Y-direction. These observations are very helpful to select the size and shape of the patch and number of the weld spot and its position on the weld spot.

\section{Conclusions}

The FE simulations of forming processes are helpful to reduce the lead time in the tool design and development stage. The accuracy of the FE simulation is strongly dependent on the material modelling and discretization level. Mechanical material testing, material properties, and its influence on the sheet metal forming have been mentioned in detail.

The forming issues in the manufacturing of aluminium (6xxx) panel have been analysed by sigma optimisation FE simulations. The springback in the aluminium panel has been calculated and successfully compensated in multiple iterations. The parametric study shows that a higher value of the coefficient of friction results in a lower springback. This means that the existence of friction is beneficial to reduce the rebound. It is also observed that springback linearly increases with an increase of clearance. The mesh sensitivity analysis shows that the element size strongly affects the converged value of results. An element size of $20 \mathrm{~mm}$ is essential to converge the springback results in this case.
In the second case study, a formability test of a patchwork blank during hot stamping has been analysed by a thermo-mechanical coupled FE simulation. The thinning and wrinkling zone in the deformed component has been analysed. The cross-sectional analysis shows that wrinkles occur in the middle region, which can be avoided by an optimisation of the blank holding force and weld-spot design.

Funding. Open access funding provided by Montanuniversity Leoben.

Open Access This article is distributed under the terms of the Creative Commons Attribution 4.0 International License (http://creativecommons. org/licenses/by/4.0/), which permits unrestricted use, distribution, and reproduction in any medium, provided you give appropriate credit to the original author(s) and the source, provide a link to the Creative Commons license, and indicate if changes were made.

\section{References}

1. Kumar, M.; Ross, N. G.: Investigations on the Hot Stamping of AW7921-T4 Alloy Sheet, Advances in Materials Science and Engineering, 2017 (2017), ID 767921

2. Kumar, M. Kirov, G: Grabner, F; Mukeli, E: Sheet Forming Processes for AW-7xxx Alloys: Relevant Process Parameters, Materials Science Forum, 879 (2017), pp 1036-1042

3. Zuo, J.; Hou, L.; Shi, J.; Cui, H.; Zhuang, L.; Zhang, J.: The mech anism of grain refinement and plasticity enhancement by an improved thermomechanical treatment of $7055 \mathrm{Al}$ alloy, Materials Science \& Engineering, 702 (2017), pp 42-52

4. Bruschi, S.; Altan, T.; Banabic, D.; Bariani, P. F.; Brosius, A.; Cao J.: Ghiotti, A, Khraisheh, M.; Merklein, M.; Tekkaya, A. E.: Testing and modelling of material behaviour and formability in sheet metal forming, CIRP Annals - Manufacturing Technology, 63 (2014), pp 727-749

5. Liao, K. C.; Pan, J.; Tang, S. C.: Effects of yield surface shape on sheet metal forming simulations, Int. Journal for Numerical Methods in Engineering, 41 (1998), pp 559-584

6. https://www.autoform.com (11.12.2017)

7. Dawson, P. R.; MacEwen, S. R.; Wu, P. D.: Advances in sheet metal forming analyses: dealing with mechanical anisotropy from crystallographic texture, Int. Materials Reviews, 48 (2003), pp 86-121

8. Hou, Y.; Min, J.; Lin, J.; Liu, Z.; Carsley, J. E.; Stoughton, T. B.: Springback prediction of sheet metals using improved material models, Procedia Engineering, 207 (2017), pp 173-178

9. Gorji, M.; Berisha, B.; Hora, P.; Barlat, F.: Modeling of localization and fracture phenomena in strain and stress space for sheet metal forming, Int. Journal of Material Forming, 9 (2016), pp 573-584

10. Erdin, M.E.; Atmaca, A.: Effects of Holding Force on the Springback Behaviour of Annealed Aluminum Plates, Procedia Engineering, 149 (2016), pp 56-61

11. Allen, M.; Dutton, T; Oliveira, M.; Hazra, S.; Adetoro, O.; Das, A.; Cardoso, R.: Benchmark 2 - Springback of a Jaguar Land Rover Aluminium Panel, Numisheet Conf. 2016, J. of Physics; Conf. Serie, 734 (2016), 022002

12. Mori, K.; Bariani, P. F; Behrens, B.-A.; Brosius, A.; Bruschi, S. Maeno, T.; Merklein, M.; Yanagimoto, J.: Hot stamping of ultrahigh strength steel parts, CIRP Annals - Manufacturing Technology, CIRP-1704, 2017

13. Lei, C.; Xing, Z.; Xu, W.; Hong, Z.; Shan, D.: Hot stamping of patchwork blanks: modelling and experimental investigation, Int. Journa of Advanced Manufacturing Technology, 92 (2017), pp 2609-2617

14. Ahmad, M. A.; Zakaria, A.: Optimization of Spot-welds on Patchwork Blank for Hot Forming Process, Applied Mechanics and Materials, 606 (2014), pp 177-180

15. Alghtani, A. H.: Analysis and Optimization of Springback in Sheet Metal Forming, PhD thesis, Doctor of Philosophy, The University of Leeds, School of Mechanical Engineering, 2015 